\title{
Evaluation of the role of the Endoplasmic Reticulum-Golgi transit in the biogenesis of peroxisomal membrane proteins in wild type and peroxisome biogenesis mutant $\mathrm{CHO}$ cells
}

\author{
ANDRÉS TORO ${ }^{1}$, CRISTIAN ARREDONDO $^{1}$, GONZALO CÓRDOVA $^{1}$, \\ CLAUDIA ARAYA ${ }^{1}$, JOSÉ L PALACIOS ${ }^{2}$, ALEJANDRO VENEGAS $^{2}$, \\ MASASHI MORITA ${ }^{3}$, TSUNEO IMANAKA ${ }^{3}$, and MANUEL J SANTOS ${ }^{1}$
}

\footnotetext{
${ }^{1}$ Departamento de Biología Celular y Molecular.

${ }^{2}$ Departamento de Microbiología y Genética Molecular, Facultad de Ciencias Biológicas, P. Universidad Católica de Chile, Santiago, Chile.

${ }^{3}$ Department of Biological Chemistry, Graduate School of Medicine and Pharmaceutical Sciences, University of Toyama, Toyama, Japan.
}

\begin{abstract}
Peroxisomes are thought to be formed by division of pre-existing peroxisomes after the import of newly synthesized proteins. However, it has been recently suggested that the endoplasmic reticulum (ER) provides an alternative de novo mechanism for peroxisome biogenesis in some cells. To test a possible role of the ERGolgi transit in peroxisome biogenesis in mammalian cells, we evaluated the biogenesis of three peroxisomal membrane proteins (PMPs): ALDRP (adrenoleukodystrophy related protein), PMP70 and Pex3p in CHO cells. We constructed chimeric genes encoding these PMPs and green fluorescent protein (GFP), and transiently transfected them to wild type and mutant $\mathrm{CHO}$ cells, in which normal peroxisomes were replaced by peroxisomal membrane ghosts. The expressed proteins were targeted to peroxisomes and peroxisomal ghosts correctly in the presence or absence of Brefeldin A (BFA), a drug known to block the ER-Golgi transit. Furthermore, low temperature did not disturb the targeting of Pex3p-GFP to peroxisomes. We also constructed two chimeric proteins of PMPs containing an ER retention signal "DEKKMP": GFP-ALDRPDEKKMP and myc- Pex3p-DEKKMP. These proteins were mostly targeted to peroxisomes. No colocalization with an ER maker was found. These results suggest that the classical ER-Golgi pathway does not play a major role in the biogenesis of mammalian PMPs.
\end{abstract}

Key terms: adrenoleukodystrophy, ALDRP, endoplasmic reticulum, peroxisome biogenesis, Pex3p and PMP70.

\section{INTRODUCTION}

Peroxisomes are essential and ubiquitous subcellular organelles, surrounded by a single membrane and containing a fine granular matrix (De Duve,1966). They contain different enzymes, which participate in several metabolic pathways, particularly in lipid metabolism, such as the $\beta$-oxidation of fatty acids (mainly very long chain fatty acids) and synthesis of plasmalogens (Van den Bosch et al., 1992).
In 1985, Lazarow and Fujiki postulated that peroxisomes form by growth and division of pre-existing peroxisomes, based on the findings that peroxisomal matrix and membrane proteins (PMPs) are synthesized on free ribosomes, and imported posttranslationally into pre-existing organelles with few exceptions (Lazarow and Fujiki, 1985). These proteins contain peroxisome-targeting sequences (PTS), which are required for recognizing and importing these proteins into the organelle

Correspondig author: Manuel J. Santos, MD, PhD, Departamento de Biología Celular y Molecular, Facultad de Ciencias Biológicas, P. Universidad Católica de Chile, Santiago, Chile, Casilla 114-D, Santiago, Chile. Tel.: (56-2) 686 2835; Fax (56-2) 6862824.E-mail: msantos@bio.puc.cl 
(reviewed in Heiland and Erdmann, 2005). Several mutations affecting this biogenic mechanism in animals have been described (Wanders, 2004). In humans, these mutations can produce severe (often lethal) diseases such as the Zellweger Syndrome (Santos et al., 1988), the prototype of the group of peroxisome biogenesis disorders (PBDs) (Oglesbee, 2005). The gene defects have been elucidated for the majority of PBDs (Gould and Valle, 2000; Wanders, 2004). The genes involved in peroxisome biogenesis are called PEX genes and their products, peroxins (Distel et al., 1996).

In recent years, it has been suggested in some particular cases in yeast, and even in humans, that peroxisomes may be formed by a de novo mechanism. A specific role for the endoplasmic reticulum (ER) in peroxisome biogenesis has been proposed, which may provide an alternative route for synthesis of some peroxisomal proteins (Kunau and Erdmann, 1998; Titorenko and Rachubinski, 1998a; Titorenko and Rachubinski, 2001; Hoepfner et al., 2005). For example, in Yarrowa lipolytica, two pulse-labeled PMPs (Pex2p and Pex16p), were targeted from the cytosol to the ER, and N- glycosylated in the ER and then chased to peroxisomes (Titorenko and Rachubinski, 1998b). In Hansenula polymorha, Pex $3 p$, Pex $8 p$ and Pex $14 p$ accumulated in the ER in the presence of Brefeldin A (BFA), and can be chased to peroxisomes after removal of BFA (Salomons et al., 1997). More recently, Hoepfner et al. (2005) showed that Pex3p and Pex19p were initially synthesized in close association to the ER in Saccharomyces cerevisiae. In animal cells, PMP50 was found to be preferentially synthesized on ER-bound ribosomes in rat liver (Bodnar and Rachubinski, 1991). Moreover, in human cells from some Zellweger patients lacking any detectable peroxisomal membrane, the transfection of the normal PEX gene restores the presence of functional peroxisomes (South and Gould, 1999). Nonetheless, drugs that block the early stages in the secretory pathway appear to have no effect on peroxisome biogenesis in mammalian cells (South and Gould, 1999; South et al., 2000).
Few experiments have been carried out to evaluate a specific role of the ER in the biogenesis of PMPs in mammalian cells (South and Gould, 1999). Very recently, Kim et al. (2006) showed that the ER plays a significant role in the biogenesis of the PMP Pex16p, in mammalian cells. Specifically, they demonstrated that this early peroxin, travels to peroxisomes after its cotranslational insertion into the ER. The fraction of the Pex $16 p$ targeted to the $\mathrm{ER}$, can leave this organelle and form new peroxisomes from it. However, at the low expression level of Pex16p, targeting of this peroxin to the ER was not detected. In addition, no evidence for ER targeting has been reported for other PMPs.

Previous data in mammalian cells, showing the lack of effect of BFA in targeting of peroxisomal proteins (South and Gould, 1999; South et al., 2000; Voorn-Brouwer et al., 2001), do not support Kim's suggestion on the role of ER in peroxisome biogenesis. To clear this point, we established a pulsechased immunofluorescence assay using cycloheximide, and examined subcellular localization of newly synthesized PMPs in presence or absence of BFA. Specifically, we evaluated the targeting of three PMPs, ALDRP (adrenoleukodystrophy related protein) (Holzinger et al., 1999), PMP70 (Imanaka et al., 1999) and Pex3p (Kammerer et al., 1998). We fused these genes to the green fluorescent protein (GFP) gene, and transiently transfected them to wild type and peroxisome biogenesis mutant $\mathrm{CHO}$ cells. We also used low temperature incubation in the transfected cells, and studied the expression of the chimeric proteins in these conditions. Finally, we constructed two additional chimeric proteins: GFP-ALDR and mycPex3p both with an ER retention signal (DEKKMP) (Jackson et al., 1990) and analyzed their localization by immunofluorescence.

Our data suggest that newly synthesized PMPs are preferentially transported to peroxisomes but not to the ER when peroxisomes and peroxisomal membrane ghosts are preexisting in $\mathrm{CHO}$ cells. In addition, the classical ER-Golgi transit appears not to be involved in the transport of the PMPs analyzed. 


\section{MATERIALS AND METHODS}

\section{Cells}

Wild type $\mathrm{CHO} \mathrm{K}-1$ cells were obtained from the American Type Culture Collection (Rockville, MD). We also used the $\mathrm{CHO}$ ZR-78 cells, which have an inactivating mutation in the PEX2 gene (Thieringer and Raetz, 1993), resulting in a deficient peroxisome biogenesis with the presence of peroxisomal membrane ghosts. The cells were maintained at $37^{\circ} \mathrm{C}$ in an atmosphere of $5 \% \mathrm{CO} 2,95 \%$ air, and in MEM $\alpha$ growth medium containing $5 \%(\mathrm{v} / \mathrm{v})$ fetal bovine serum (GIBCO), supplemented with glutamine $(1 \mathrm{mM})$, penicillin $(100 \mathrm{mg} / \mathrm{ml})$, streptomycin $(73.5 \mu \mathrm{g} / \mathrm{ml})$.

\section{Antibodies}

Five sets of antibodies were used: 1) Rabbit antiserum against rat liver PMPs (Santos et al., 1988), which cross reacts with several other mammalian PMPs, including PMPs from CHO cells (Zoeller et al., 1989); 2) Rabbit anti-human calnexin (Sigma-Aldrich, MI), 3) Mouse anti-rat PDI that crossreacts with human protein (Stressgene Inc, USA), 4) Rabbit anti-human mannosidase II and 5) human antiserum against human Golgi apparatus antigens, which morphologically recognizes the Golgi apparatus from different species. The last two antibodies were the generous gift of Dr. Alfonso González de la Rosa (Faculty of Medicine, P. Catholic University of Chile).

\section{Immunofluorescence microscopy}

The cells were grown on cover slips and subjected to indirect immunofluorescence (Santos et al., 1988). Briefly, the cells were fixed with $4 \%$ paraformaldehyde, permeabilized with $100 \%$ methanol, blocked with phosphate buffered saline containing $1 \%$ bovine serum albumin, incubated with a primary antibody and subsequently with a secondary antibody conjugated to fluorescein isothiocyanate (FITC) or Texas Red. Digital images of fluorescence were acquired on a Zeiss Axiophot microscope with an x63 immersion objective and the 14- bit Axiocam camera, and then transferred to a computer workstation running Axiovision imaging software. The number of peroxisomes was quantified following the procedure described by Wei et al. (2000). Data are mean \pm S.E. from four separate experiments performed in duplicate. Data were evaluated statistically by using Student's $t$ test, with $p<0.05$ considered significant.

\section{Transient transfection}

$\mathrm{CHO}$ cells were seeded in complete growth medium, in $35-\mathrm{mm}$ tissue culture dishes. When the cells reached $70-80 \%$ confluence, they were transiently transfected with the genes described below using LipofectaAMINE 2000 (Life Technologies, Inc.), following the manufacturer's instructions. Then, the cells were grown at $37^{\circ} \mathrm{C}$ for $14 \mathrm{~h}$, or at temperatures that block the ER-Golgi transit $\left(10^{\circ} \mathrm{C}\right.$ and $\left.15^{\circ} \mathrm{C}\right)$, with addition of HEPES $(10 \mathrm{mM})$ directly to the medium. Then 1-2 $\mathrm{mg}$ of each plasmid was used for transfections.

\section{Treatment with cycloheximide (CHX) and BFA}

In some experiments, transfected cells were incubated in the presence of $1 \mu \mathrm{g} / \mathrm{ml} \mathrm{CHX}$ (Yamasaki et al., 1999), for $6 \mathrm{~h}$ after transfection. Then, BFA was added to the medium (10 $\mu \mathrm{g} / \mathrm{ml}$ final concentration) (Fujiwara et al., 1988) and the cells were incubated in the presence of both $\mathrm{CHX}$ and BFA for $1 \mathrm{~h}$. Finally, cells were further incubated in the presence of BFA (alone) for an additional $6 \mathrm{~h}$. At the end of this treatment, the cells were fixed with $4 \%$ paraformaldehyde and analyzed directly under the fluorescence microscope or processed for indirect immunofluorescence.

\section{Gene constructions}

pALDR-GFP: cDNA cloning of ALDR was done using PCR-based protocols. PCR was performed with a human brain cDNA library (Takara, Kyoto, Japan) as template using two sets of oligonucleotide primers designed on the basis of a human ALDR cDNA sequence reported by Holzinger et 
al. (1997). The amplification product with an ALDR cDNA-specific forward primer (5'-ATTTGCTGGGGATTTCTGTG-3', nt 61-81) and reverse primer (5'GTATAACAGAATGTCTTTGAGC-3', nt 2400-2421) was used as template for nested PCR. Numbers in the parentheses are the bp numbers based on a human ALDR cDNA sequence (Gene Bank Accession No. AJ000327). Nested PCR was performed with a forward primer (5' - TGGGTAGTCG ACAAAATGACACATATGCTAAATGC3', nt 133-155) having a Sal I- recognition site, and a reverse primer (5'- CAATCT AGATTAAGATGTCTCATCTTCATTT-3', nt 2337-2358) having a Xba I- recognition site. The amplified PCR fragment was directly cloned into the $\mathrm{Sal}$ I and $\mathrm{Xba}$ I sites of pMAM2-BSD vector (Kakenseiyaku, Tokyo, Japan). The insert was then removed from this construct by digestion with Nhe I and the $2.1 \mathrm{~kb}$ fragment containing the open reading frame but lacking the sequence encoding the $\mathrm{COOH}$ terminal 33 amino acid residues, was ligated to the Nhe I site of pEGFP-N1 vector (Clontech). A restriction map was used to test the proper orientation of the insert. cDNA sequence was confirmed by the dye-terminator cycle sequencing method using a DNA sequencer (ABI PRISM 310, PE Applied Biosystems). The final chimeric gene pALDR-GFP2 has $95 \%$ of the cDNA of the ALDR protein.

pGFP-PMP70(1-180): This construction was carried out by PCR using the pMAM2BSD-PMP70 plasmid as the template using two sets of oligonucleotide primers; a forward primers (5'-ATACCGGAATTCAA TGGCGGCCTTCAGCAAG-3') having a EcoR I-recognition site and a reverse primer (5' - TAGTCGGGGTACCTCAG TTGTCCAGATTCCCCTT-3') having a Kpn I-recognition site. The amplification product containing only the first sequence encoding 180 aa of the PMP70 amino terminus, was digested with EcoR I and $K p n$ I enzymes and ligated to the pEGFPC1 vector (Clontech).

pPEX3-GFP: This construction was carried out by PCR using the pcDNA3PEX3 plasmid (a generous gift of Dr. S.J. Gould, Dept. of Biological Chemistry, The
Johns Hopkins University School of Medicine, USA) as the template using two sets of oligonucleotide primers; a forward primer (5'-TCAGCTAGCATGCTGAGGT CTGTA- 3') having a Nhe I-recognition site and a reverse primer (5' GCAGGTACCTCTTTCTCCAGTTGCTG3') having a Kpn I-recognition site. The amplification product containing the full length of the human PEX3 gene was digested with Nhe I and Kpn I enzymes, and ligated to the pEGFP-N1 vector (Clontech).

p A L D R - G F P - D E K K M P : T h i s construction was carried out by PCR using a forward primer (5'-AGACTCGTCGACA TGACACATATGCTAAATGCAGC-3') having a $S a l$ I-recognition site and a reverse primer (5' - GAGTCTGGATCCTTAGGGC ATCTTCTTCTCGTCAGATGTCTCATCTTC ATTTTTA ATTGTTTTCAG-3') having a BamH I-recognition site. The amplification product was digested with Sal I and BamH I enzymes and ligated to the pEGFP-N1 vector (Clontech).

pXS/ManII-GFP: The pXS/ManII-GFP containing the mannosidase II and the GFP genes was a generous gift of Dr. Elizabeth Lippincott-Schwartz (Cell Biology and Metabolism Branch, National Institute of Child Health and Human Development, National Institutes of Health, Bethesda, USA) pmycPEX3-DEKKMP:This construction was carried out by PCR using the pcDNA3PEX3 plasmid as the template using two sets of oligonucleotide primers; a forward primer (5'-ATACCATGGACATGCTGAG GTCTGTA-3') and a reverse primer (5' CGGCCATGGTCAAGGCATTTTTCTC GTCTTTCTCCAGTTGCTGAGGGGTACT AAAAGCTTCATA-3') having a Nco Irecognition site. The amplification product, containing the complete sequence of the human PEX3 gene and the sequence DEKKMP at the amino terminus, was digested with the Nco I enzyme and ligated into the vector $\mathrm{pCS} 2+\mathrm{MT}$, a generous gift of Dr. Estela Andrés (Department of Cellular and Molecular Biology, Faculty of Biological Sciences, Catholic University of Chile). This vector has the myc sequence immediately after the promoter, and allows to fuse it to the 5' end of the human PEX3DEKKMP gene. 


\section{RESULTS}

ALDRP-GFP is targeted to peroxisomes in basal conditions. The ALDR-GFP gene was transiently transfected to $\mathrm{CHO}$ cells and the protein expression was followed by fluorescence microscopy at $48 \mathrm{~h}$ posttransfection. As shown in Figure 1c, the fluorescence pattern of ALDRP-GFP is punctate, in contrast to the cytosolic distribution of GFP (Fig. 1a). In order to confirm the peroxisomal localization of ALDRP-GFP, we carried out indirect immunofluorescence of the transfected cells with an antiserum against PMPs (Fig. 1d) (Zoeller et al., 1989). The comparison of panels $c$ and d, clearly shows the colocalization of PMPs and ALDRP-GFP.

ALDRP-GFP is targeted to peroxisomes and peroxisome membrane ghosts in the presence or absence of $B F A$

To test an eventual involvement of the ERGolgi transit in the targeting of ALDRPGFP, CHO cells transiently expressing ALDRP-GFP were treated with BFA, a drug known to block the transit between the ER and the Golgi apparatus (Fujiwara et al., 1988). Before carrying out these treatments, several experimental settings were established.
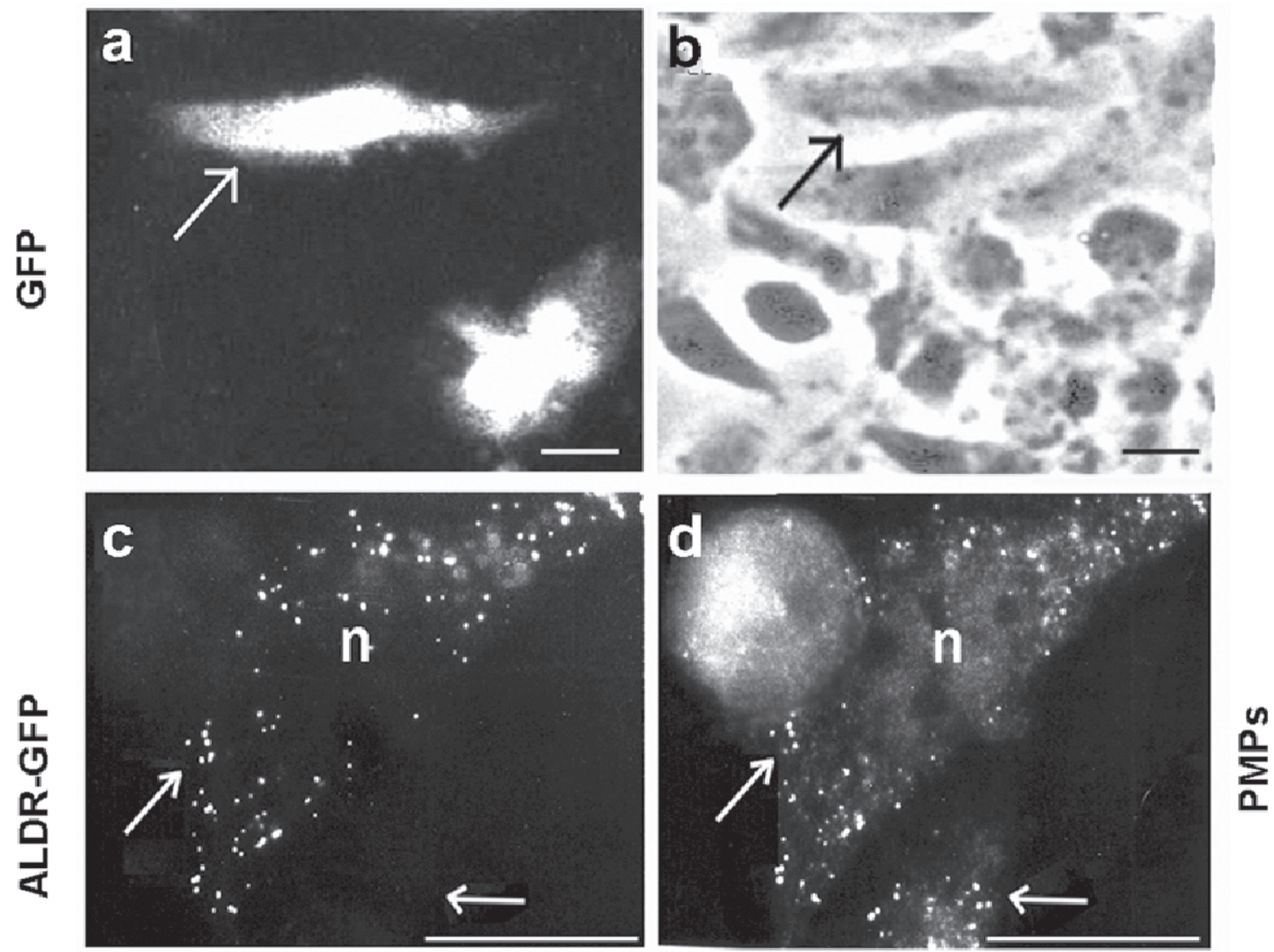

Figure 1: Subcellular localization of GFP and ALDRP-GFP in CHO cells. Wild type CHO cells were grown on coverslips and transfected with $1 \mu \mathrm{g}$ of pEGFP-N1 plasmid (a and b) or pALDRGFP plasmid (c and d). After $48 \mathrm{~h}$, the cells were fixed and analyzed directly by fluorescence microscopy (a) or processed for indirect immunofluorescence, using a primary antiserum against PMPs and a secondary antibody conjugated to Texas Red (c and d) as indicated in Materials and Methods. Panel $b$ is a phase-contrast image of the cells shown in panel a. Arrows in a and $b$ show a cell transfected with GFP. Arrows in c and d show peroxisomes. Bar $=20 \mu \mathrm{m}$. 
First, we incubated wild type cells with or without BFA and carried out immunofluorescent detection of mannosidase II, a resident marker enzyme of the Golgi apparatus. As shown in Figure 2b, BFA disassembled the normal appearance of the Golgi apparatus. Furthermore, this BFA incubation does not affect the number of peroxisomes in cells (Fig. 2, c-e).

\section{Golgi Apparatus}

- BFA

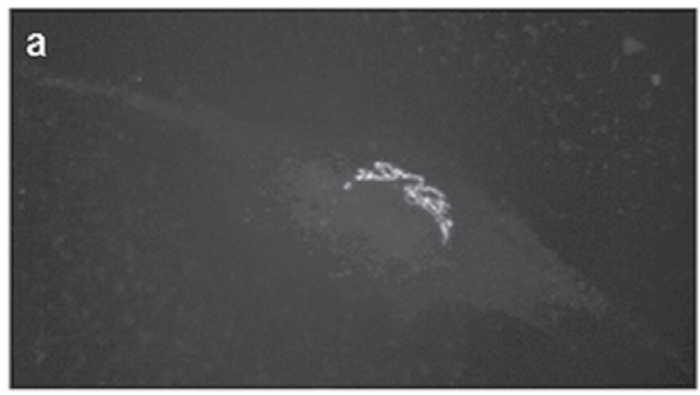

+ BFA

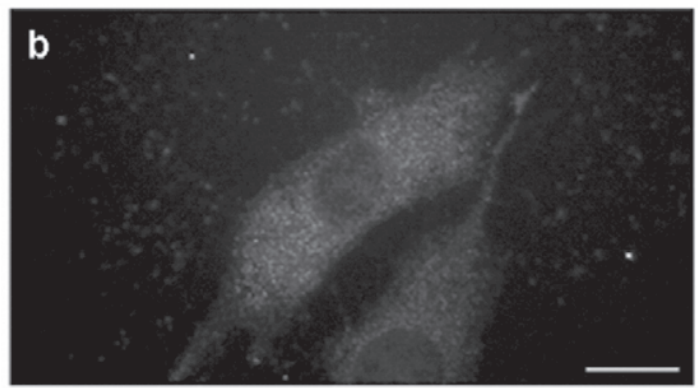

\section{Peroxisomes}

c

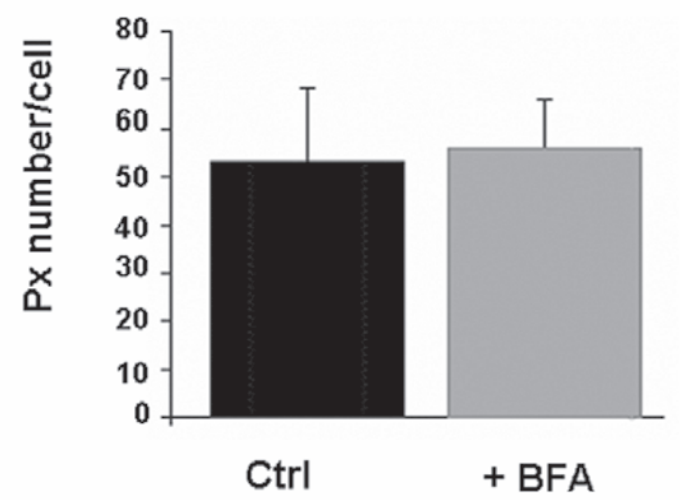

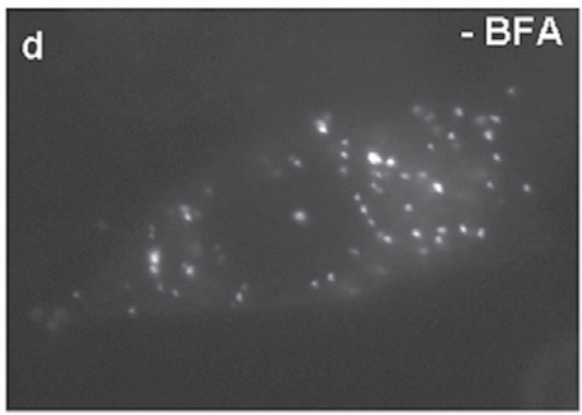

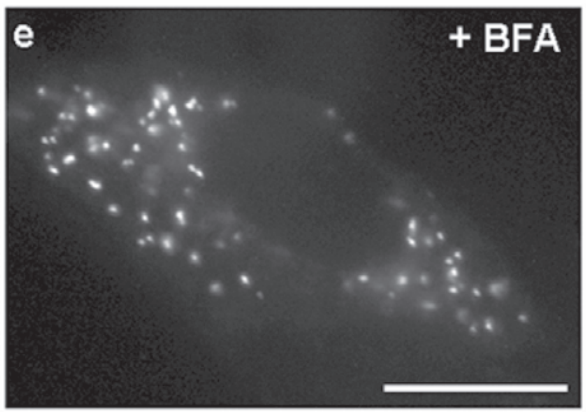

Figure 2: Effect of BFA on Golgi apparatus and peroxisomes. Wild type CHO cells were grown on coverslips. After $18 \mathrm{~h}$, the cells were incubated in the absence (a) or presence (b) of BFA (10 $\mu \mathrm{g} / \mathrm{ml}$ ) for $6 \mathrm{~h}$, and then analyzed indirectly by immunofluorescence using antibodies, antimannosidase II ( $a$ and $b$ ) or anti-PMPs ( $d$ and e). The number of peroxisomes was quantified following the procedure described by Wei et al. [24]. BFA treatment disassembles the Golgi apparatus and has no effect on the number of peroxisomes (c). Bar $=20 \mu \mathrm{m}$. 
Second, in order to inhibit protein synthesis and reinitiate it, in the presence or absence of BFA, we first set the conditions to block the expression of GFP. As shown in Figure 3a, CHO cells transfected with the pEGFP-N1 plasmid show an intense cytoplasmic fluorescence. This signal was completely abolished when the transfected cells were incubated in the presence of cycloheximide $(\mathrm{CHX})$, a protein synthesis inhibitor (Fig. 3c). However, the signal reappeared when the cells incubated with
CHX were washed and further incubated in the absence of CHX (Fig. 3e). In addition, to test the specificity of the Golgi apparatus labeling by the anti-Golgi antibody, $\mathrm{CHO}$ cells were transfected with the pXS/ MannII-GFP plasmid, which express the Golgi marker enzyme mannosidase II-GFP and were subjected to indirect immunofluorescence. A clear colocalization of these two fluorescence signals of antiGolgi antibody and mannosidase II-GFP was detected (Fig. 4, $\mathrm{m}$ and $\mathrm{n}$ ).
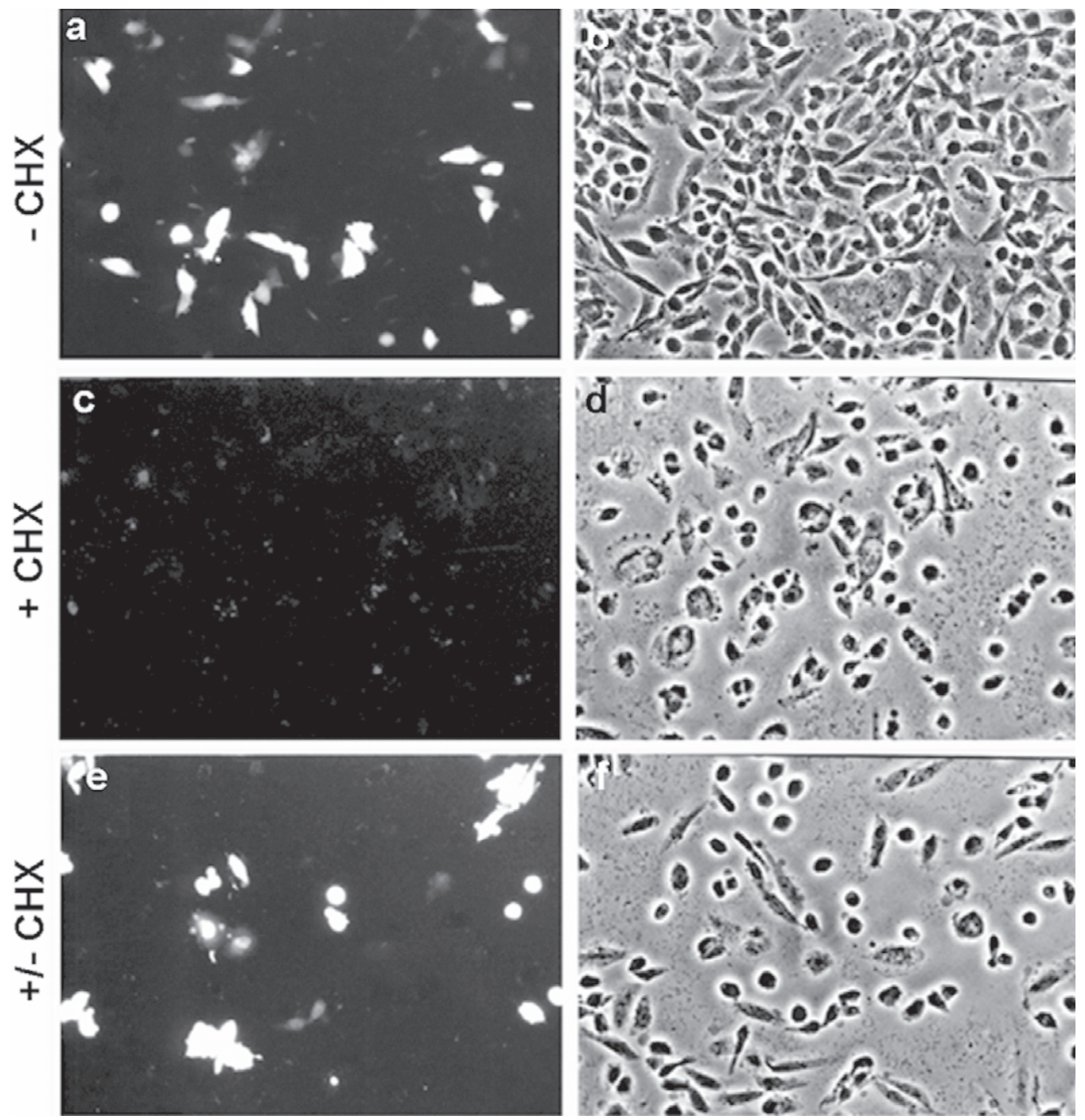

Figure 3: Expression of GFP in the absence or presence of CHX. Wild type CHO cells were transfected with $1 \mu \mathrm{g}$ of pEGFP-N1 plasmid. After $24 \mathrm{~h}$, the cells were incubated in the absence (a and b) or presence (c and d) of CHX $(10 \mu \mathrm{g} / \mathrm{ml})$ for $7 \mathrm{~h}$. Then the cells were washed and further incubated in the absence of CHX, for additional $7 \mathrm{~h}$ (e and f). Panels b, $\mathrm{d}$ and $\mathrm{f}$ are phase-contrast images of the cells. 

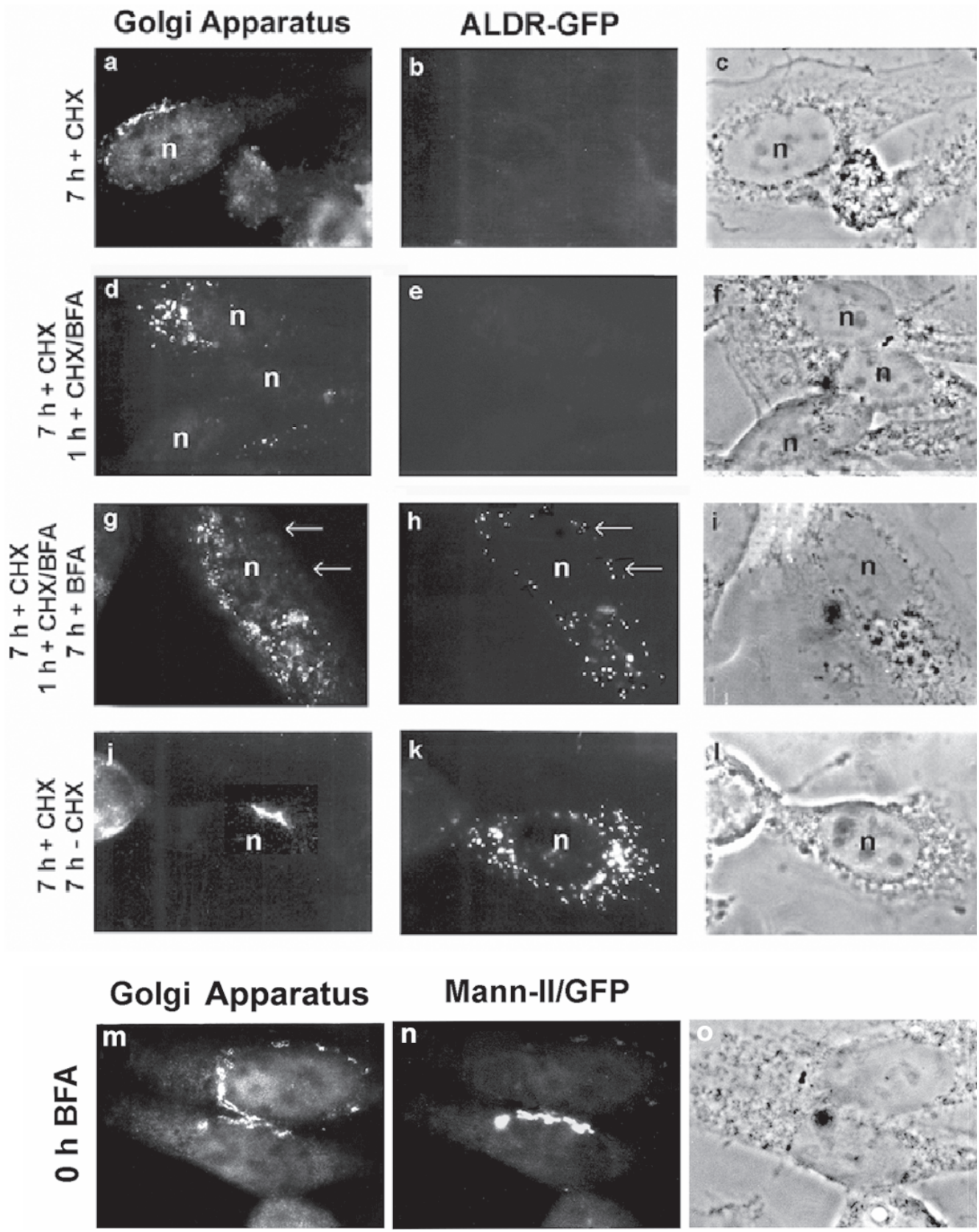

\section{Mann-II/GFP}
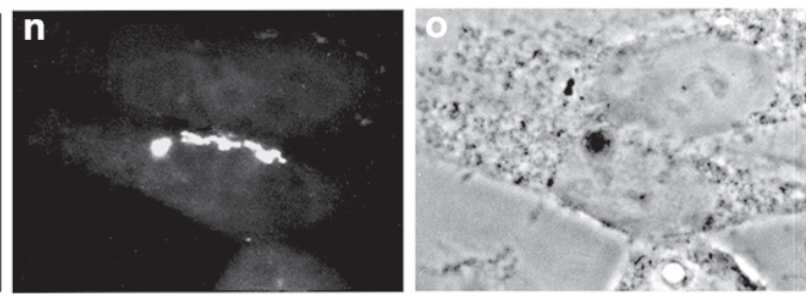

Figure 4: Effect of BFA and CHX on the synthesis of ALDRP-GFP. Wild type CHO cells were transfected with $1 \mu \mathrm{g}$ of pALDR-GFP plasmid. After $6 \mathrm{~h}$, the cells were incubated in the presence (a-c) of CHX $(10 \mu \mathrm{g} / \mathrm{ml})$ for $7 \mathrm{~h}$. A batch of these cells was further incubated with BFA $(10 \mathrm{mg} / \mathrm{ml})$ for an additional hour (d-f). A set of these latter cells was washed and further treated with BFA for $6 \mathrm{~h}$ (in the absence of $\mathrm{CHX}$ ) (g-i). Cells treated for $7 \mathrm{~h}$ in the presence of $\mathrm{CHX}$, were washed and further incubated in the absence of $\mathrm{CHX}$ for an additional $7 \mathrm{~h}(\mathrm{j}-1)$. At the end of the experiment, the cells were fixed and processed for an indirect immunofluorescence, using a human antiserum which morphologically recognizes the Golgi apparatus (a, $d, g$ and $j$ ). The specificity of the Golgi apparatus labeling is shown in panels $\mathrm{m}$ and $\mathrm{n}$ : CHO cells were transfected with the $\mathrm{pXS} / \mathrm{mannII}$ GFP plasmid to express mannosidase II-GFP (n) and subjected to indirect immunofluorescence using the human antiserum against Golgi apparatus antigens $(\mathrm{m})$. Panels $\mathrm{c}, \mathrm{f}, \mathrm{i}$ and $\mathrm{l}$ are phase contrast images of the cells. $\mathrm{Bar}=20 \mu \mathrm{m}$. 
Then, CHO cells transfected with the pALDR-GFP plasmid were incubated with $\mathrm{CHX}$ for $7 \mathrm{~h}$ to block protein synthesis (Fig. 4). As shown in Figure 4b, no ALDRP-GFP signal was detected, but Golgi apparatus appears normally (Fig. 4a). The addition of BFA for $1 \mathrm{~h}$ to block the ER-Golgi transit in the presence of $\mathrm{CHX}$, had a dramatic effect on Golgi morphology (Fig. 4d), but the synthesis of ALDRP-GFP was still blocked (Fig 4e). CHX was then removed and cells were further incubated for additional $7 \mathrm{~h}$ in the presence of BFA. As shown in Figure 4g, the Golgi apparatus is completely disassembled and in contrast, ALDRP-GFP synthesis has been reinitiated and the protein was targeted to peroxisomes (Fig. 4h). When the fluorescence pattern of ALDR-GFP and Golgi marker were merged, no colocalization was detected (data not shown). As a wild type, the cells transfected with the pALDR-GFP gene were incubated for $7 \mathrm{~h}$ in the presence of $\mathrm{CHX}$, then washed out and further incubated for an additional 7 $\mathrm{h}$ in the absence of CHX. In these conditions ALDRP-GFP was also targeted to peroxisomes (panel 4k) and the Golgi apparatus appeared normally, as expected (panel 4j).

Furthermore, we studied the targeting of ALDRP-GFP protein to peroxisomal membrane ghosts in peroxisome biogenesis mutant $\mathrm{CHO}$ cells. We used the $\mathrm{CHO}$ mutant cell line ZR78, which carries a mutation in the PEX2 gene, involved in peroxisome biogenesis (Thieringer and Raetz, 1993). This cell line shows the presence of peroxisome membrane ghosts, similar to the human cells obtained from Zellweger patients (Zoeller et al., 1989). As shown in Figure 5, the ALDRP-GFP was targeted to normal peroxisomes in wild type $\mathrm{CHO}$ cells and to peroxisomal membrane ghosts in the ZR78 mutant cell line, in the presence or absence of BFA.

GFP-PMP70(1-180) and Pex3p-GFP are targeted to peroxisomes and peroxisome membrane ghosts in the presence or absence of BFA in $\mathrm{CHO}$ cells

We also evaluated the biogenesis of two other PMPs, PMP70 and Pex3p. PMP70 is one of the major PMP of the mammalian peroxisomal membrane. The membrane peroxisomal targeting sequence (mPTS) involves a region contained in the 180 amino acids of the amino-terminal (Biermanns and Gartner, 2001; Kashiwayama et al., 2005). We constructed a chimeric gene fusing the first 180 amino acids of the PMP70 gene to GFP. Results of transfection of this gene to wild type and ZR78 mutant $\mathrm{CHO}$ cells are shown in Figure 6. GFP-PMP70 (1-180)GFP was targeted to normal peroxisomes in wild type $\mathrm{CHO}$ cells and to peroxisomal membrane ghosts in the ZR78 mutant cell line, in the presence or absence of BFA.

Pex $3 p$ is an essential PMP for peroxisome biogenesis and is required at the initial steps of peroxisome membrane biogenesis in yeast and mammalian peroxisomes. We fused the PEX3 gene to GFP and transfected this chimeric gene to wild type and ZR78 mutant $\mathrm{CHO}$ cells. As shown in Figure 7, the Pex3p-GFP was targeted to normal peroxisomes and to peroxisomal membrane ghosts, in the presence or absence of BFA. These results suggest that ER-Golgi transit does not involved in targeting of ALDRP-GFP, GFPPMP70 (1-180) and Pex3p-GFP to peroxisomes.

Effect of the temperature to the targeting of Pex3p in wild type CHO cells

Hoepfner et al. demonstrated in yeast that the early peroxin Pex3p is targeted to the ER in wild type and PEX3 mutant cells (Hoepfner et al., 2005). These authors showed that Pex $3 p$ concentrated in foci of ER, which then bud off and mature into fully functional peroxisomes. Keeping this in mind, we wanted to evaluate the effect of temperature on the fate of Pex3p-GFP. For this, we tested whether a temperature that inhibits the ER-Golgi transit (Mezzacasa and Helenius, 2002), can cause the arrest of Pex3p in the ER. First, in order to test if temperature shift affects the expression of Pex3p-GFP, we expressed GFP in $\mathrm{CHO}$ wild type cells and then incubated the cells at different temperatures. The expression of GFP at $10^{\circ} \mathrm{C}$ and $15^{\circ} \mathrm{C}$ for $5 \mathrm{~h}$, was easily detected in the cells, although with a lower 


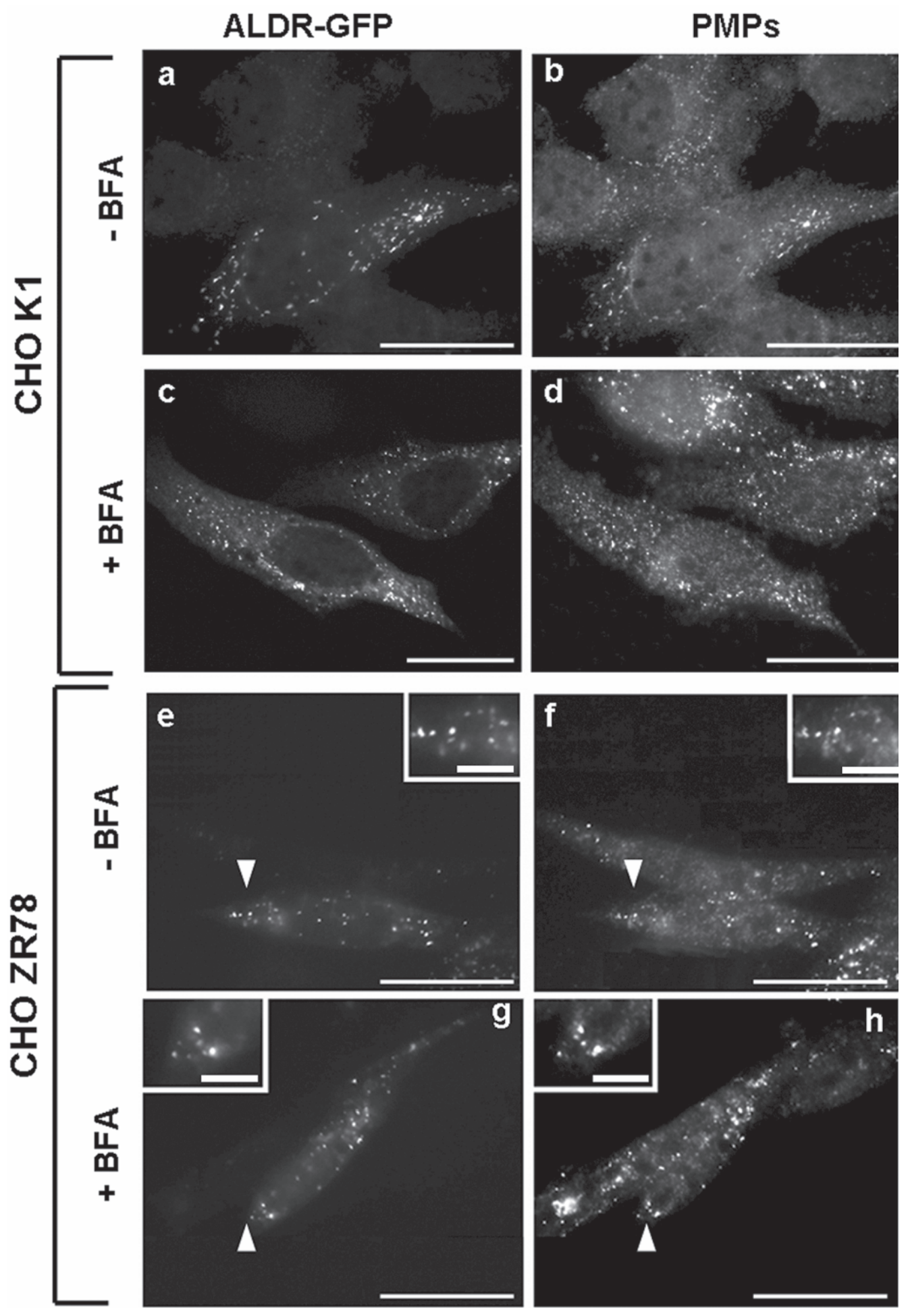

Figure 5: Effect of BFA on the targeting of ALDR-GFP in wild type and peroxisome biogenesis mutant CHO cells. Wild type (a-d) and peroxisome biogenesis mutant (ZR 78) (e-h) CHO cells were transiently transfected with the ALDR-GFP gene and subsequently treated for $6 \mathrm{~h}$ with (c and $\mathrm{d}$; $\mathrm{g}$ and $\mathrm{h}$ ) or without ( $\mathrm{a}$ and $\mathrm{b}$; e and f) BFA. Fluorescence signal of the ALDR-GFP ( $\mathrm{a}, \mathrm{c}$, e and g) was detected and endogenous PMPs were immunodetected using indirect immnufluorescence (b, d, $\mathrm{f}$ and $\mathrm{h})$. Bar $=20 \mu \mathrm{m}$. The areas indicated by arrowheads are expanded in insets. Inset bar $=5 \mu \mathrm{m}$. 


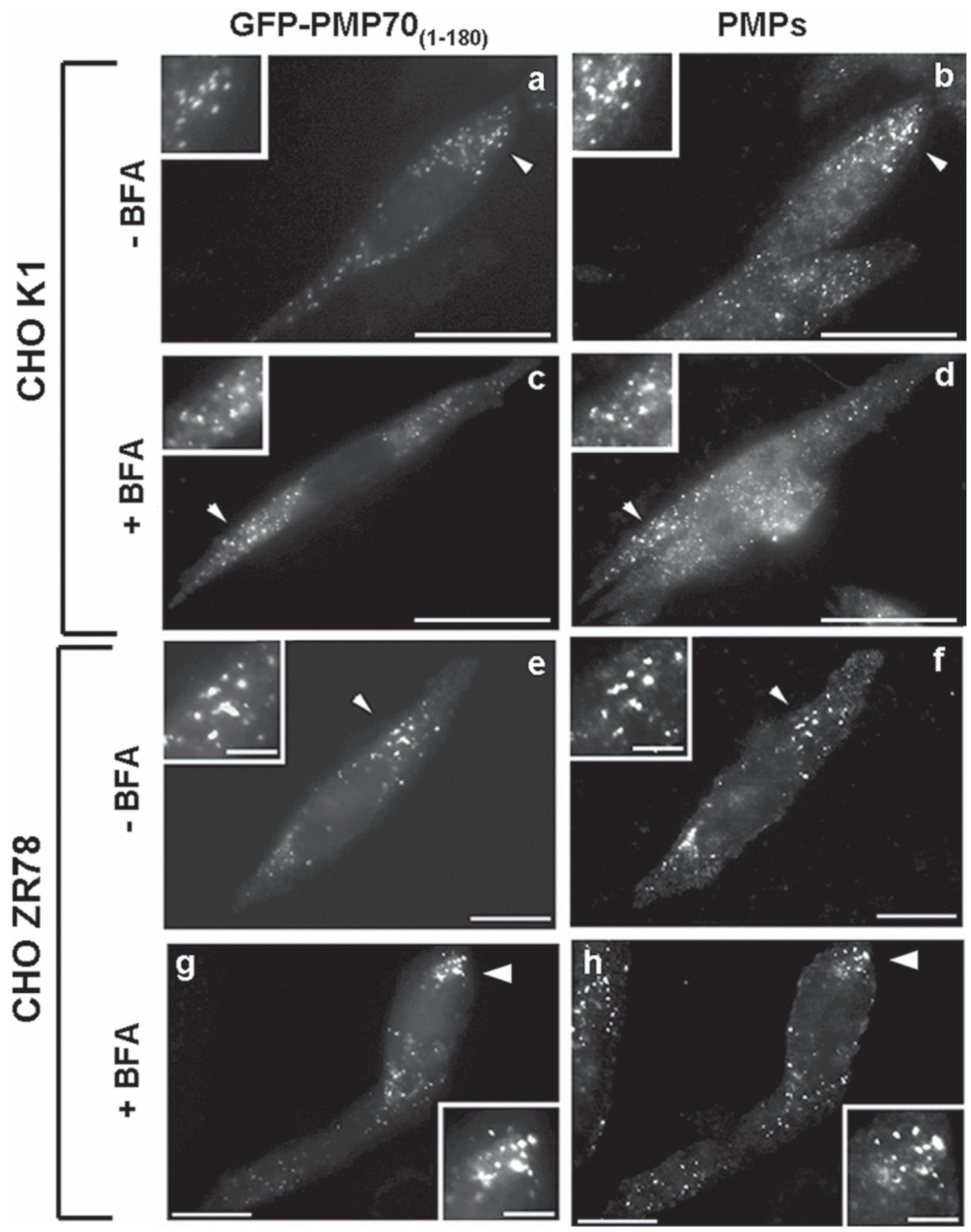

Figure 6: Effect of BFA on the targeting of GFP-PMP70 (1-180) in wild type and peroxisome biogenesis mutant $\mathrm{CHO}$ cells. Wild type (a-d) and peroxisome biogenesis mutant (ZR 78) (e-h) CHO cells were transiently transfected with GFP- PMP70 (1-180) gene and subsequently treated for $6 \mathrm{~h}$ with ( $\mathrm{c}$ and $\mathrm{d} ; \mathrm{g}$ and $\mathrm{h}$ ) or without ( $\mathrm{a}$ and $\mathrm{b}$; e and $\mathrm{f}$ ) BFA. Fluorescence signal of the GFPPMP70 (1-180) (a, c, e and g) was detected and endogenous PMPs were immunodetected using indirect immnufluorescence $(\mathrm{b}, \mathrm{d}, \mathrm{f}$ and $\mathrm{h})$. Bar $=20 \mu \mathrm{m}$. Inset bar $=5 \mu \mathrm{m}$. 
PEX3-GFP
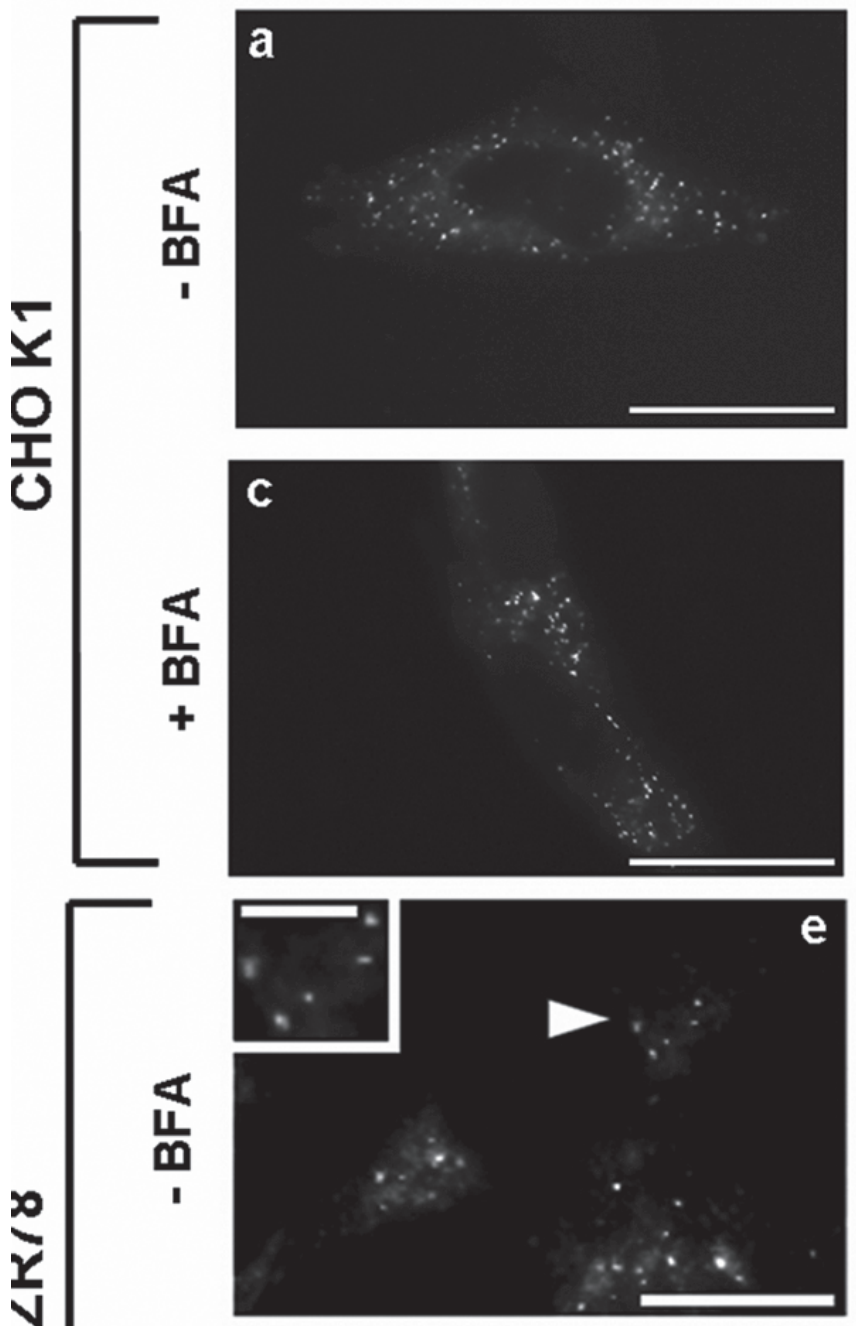

$\frac{2}{3}$

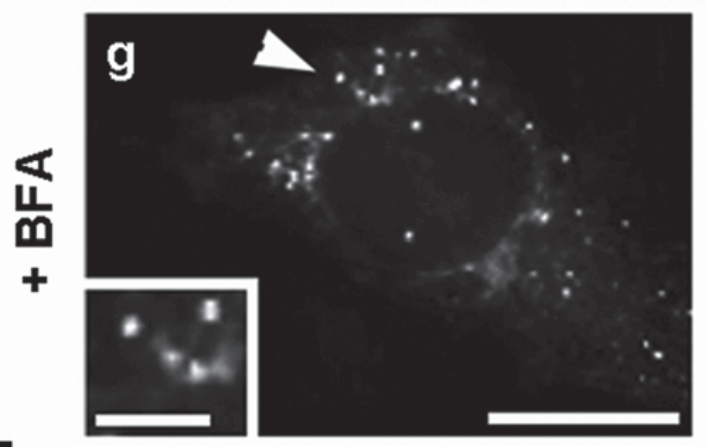

PMPs
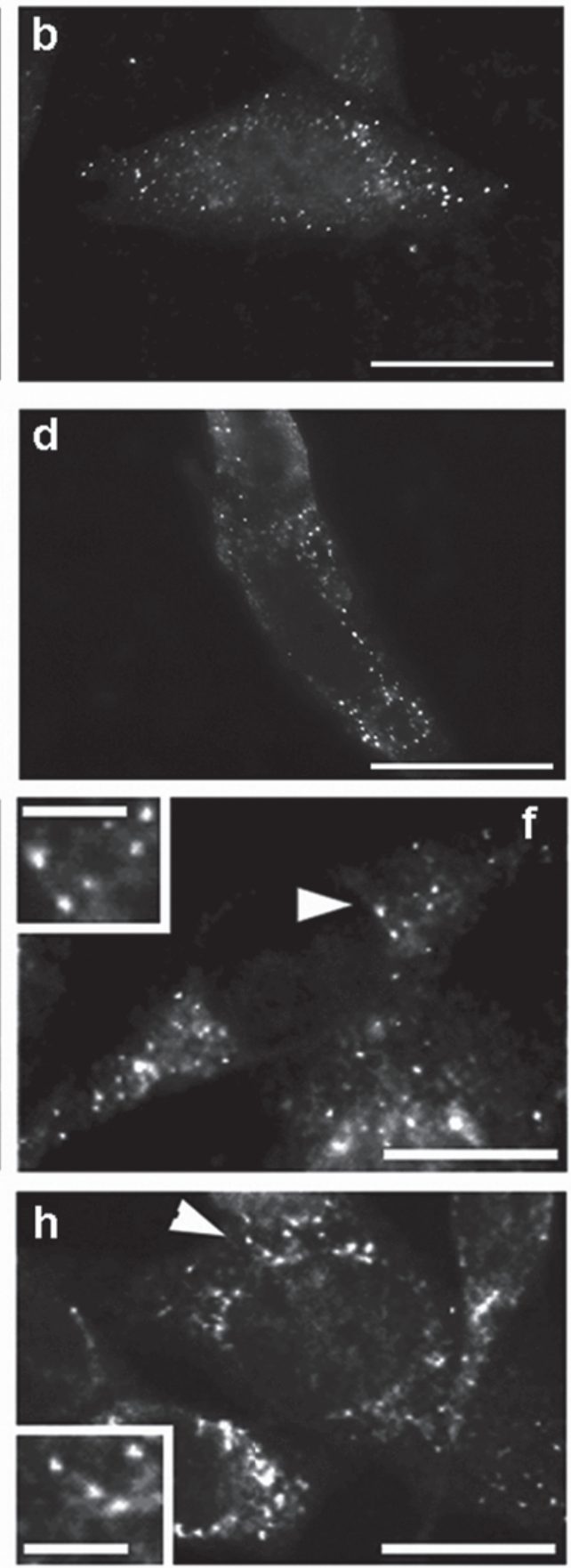

Figure 7: Effect of BFA on the targeting of Pex3p-GFP in wild type and peroxisome biogenesis mutant CHO cells. Wild type (a-d) and peroxisome biogenesis mutant (ZR 78) (e-h) CHO cells were transiently transfected with the PEX3-GFP gene and subsequently treated for $6 \mathrm{~h}$ with (c and $\mathrm{d}$; $\mathrm{g}$ and $\mathrm{h}$ ) or without (a and b; e and f) BFA. Fluorescence signal of the Pex3p-GFP (a, c, e, and g) was detected and endogenous PMPs were immunodetected using indirect immnufluorescence (b, $d$, $\mathrm{f}$ and $\mathrm{h})$. Bar $=20 \mu \mathrm{m}$. Inset bar $=5 \mu \mathrm{m}$. 
intensity than at control temperature (Figure 8, b, d and f). Then, we expressed Pex3p-GFP in CHO cells and incubated the cells at low temperatures for $5 \mathrm{~h}$. However, we could not observe an ER-like pattern for Pex3p-GFP (Fig. 8, a, c and e). Moreover, the pattern of the signal obtained from Pex3p-GFP expression at $10^{\circ} \mathrm{C}$ or $15^{\circ} \mathrm{C}$, was very similar to that observed at $37^{\circ} \mathrm{C}$ (Fig. $8 \mathrm{e})$. These results suggest that the temperature shift does not affect the final peroxisomal localization of Pex3p-GFP.

Effect of the insertion of an ER retention signal in ALDRP and Pex3p on peroxisomal targeting

We tested the effect of inserting an ER retention signal to the targeting of ALDRP and Pex $3 \mathrm{p}$. For this, we inserted the sequence DEKKMP, which acts as an ER retention signal (Jackson et al., 1990), into the C-terminus of ALDRP-GFP and mycPex3p. This six amino acid sequence can be fused to the cytoplasmic tail of other membrane bound proteins, and ER residency is conferred (Jackson et al., 1990). It has been suggested that the $\mathrm{C}$-terminus of human Pex3 $p$ faces the cytoplasm (Soukupova et al., 1999), and a similar topology for the Cterminus of ALDRP is expected. The addition of this six residue signal (DEKKMP) to the C-terminus of our peroxisomal proteins, can retain them in the ER membrane, assuming they use the ER to reach the peroxisomal membrane.

We expressed ALDRP-GFP-DEKKMP and myc-Pex3p-DEKKMP in wild type and ZR78 CHO cells, and evaluated their subcellular localization by immunofluorescence using antibodies against PMPs or the ER-marker calnexin. As shown in Figure 9, ALDRP-GFPDEKKMP was normally targeted to peroxisomes in wild type cells, and to peroxisomal ghosts in ZR78 cells (Figs. 9, $\mathrm{a}-\mathrm{b}$ and $\mathrm{c}-\mathrm{d}$, respectively). Some diffuse cytosolic pattern was seen in some transfected cells. When the ALDRP-GFPDEKKMP signal was merged with the one of an ER marker, no co-localization was detected in CHO wild type and ZR78 cells (data not shown).
Similar results were obtained with the expression of mycPex $3 p$-DEKKMP. The protein was targeted to peroxisomes and peroxisomal ghosts, in wild type and ZR78 CHO cells (Figs. 10, a-b and e-f, respectively). A more intense staining of an extra-peroxisomal pattern was seen with mycPex3p-DEKKMP in both type of $\mathrm{CHO}$ cells (Figs 10a, c, e and g). However, when the fluorescence pattern of mycPex $3 p$ DEKKMP and calnexin was merged, no overlapping of signal was detected in wild type or ZR78 CHO cells (data not shown). These results suggest that both proteins are not retained in ER membranes, in wild type and ZR78 CHO cells.

\section{DISCUSSION}

In this study, we transiently expressed chimeric proteins of PMPs and GFP in wild type and peroxisome biogenesis mutant $\mathrm{CHO}$ cells, and examined the role of the ERGolgi transit in the biogenesis of resident PMPs using BFA. This compound is well known to block the transit between the ER and the Golgi apparatus (Fujiwara et al., 1988; Lippincott-Schwartz et al., 1889; Wieland and Harter, 1999). Specifically, it blocks the formation and budding of vesicles from the ER, by inhibition of the GDP/GTP exchange on ARF (ADP-ribosylation factor) (Helms and Rothman, 1992; Zhao et al., 1997), resulting in the disassembly of the Golgi apparatus. Such an effect was easily shown in BFA-treated CHO cells (Fig. 2).

In the experiments, first we blocked protein synthesis with $\mathrm{CHX}$ in $\mathrm{CHO}$ cells after transfection of pALDR-GFP and then restarted protein synthesis by removing $\mathrm{CHX}$, in the presence or absence of BFA. No fluorescence of GFP was detected in the cells in the presence of $\mathrm{CHX}$ and the fluorescence signal appeared after $\mathrm{CHX}$ was removed from the medium (Fig. 3), suggesting that targeting of newly synthesized ALDRP-GFP could be chased. In addition, the Golgi apparatus (Fig. 4) and peroxisomes (data not shown) appeared normal in the presence of $\mathrm{CHX}$. Further disappearance of Golgi apparatus and re-distribution of Golgi proteins to ER by BFA were not disturbed by CHX (Fig. 4). 


\section{PEX3-GFP}
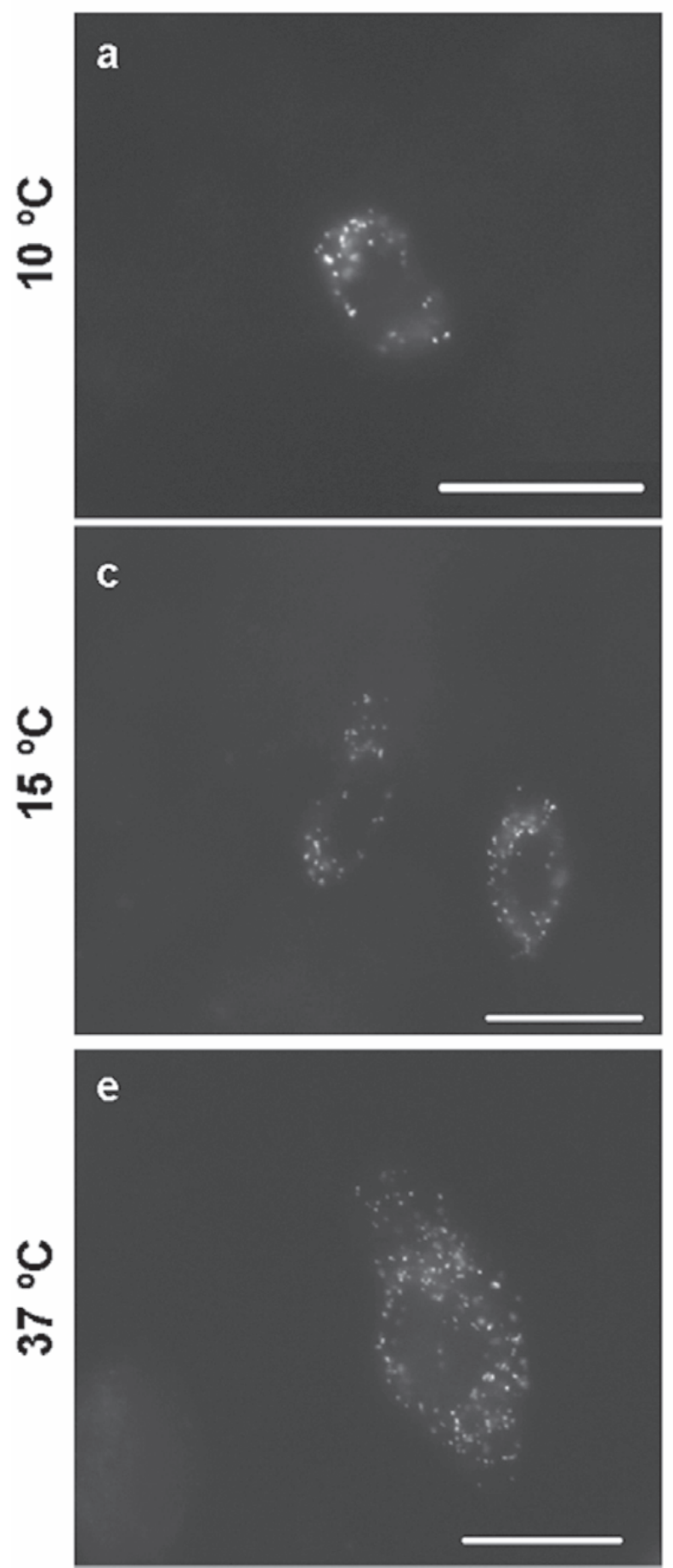

GFP
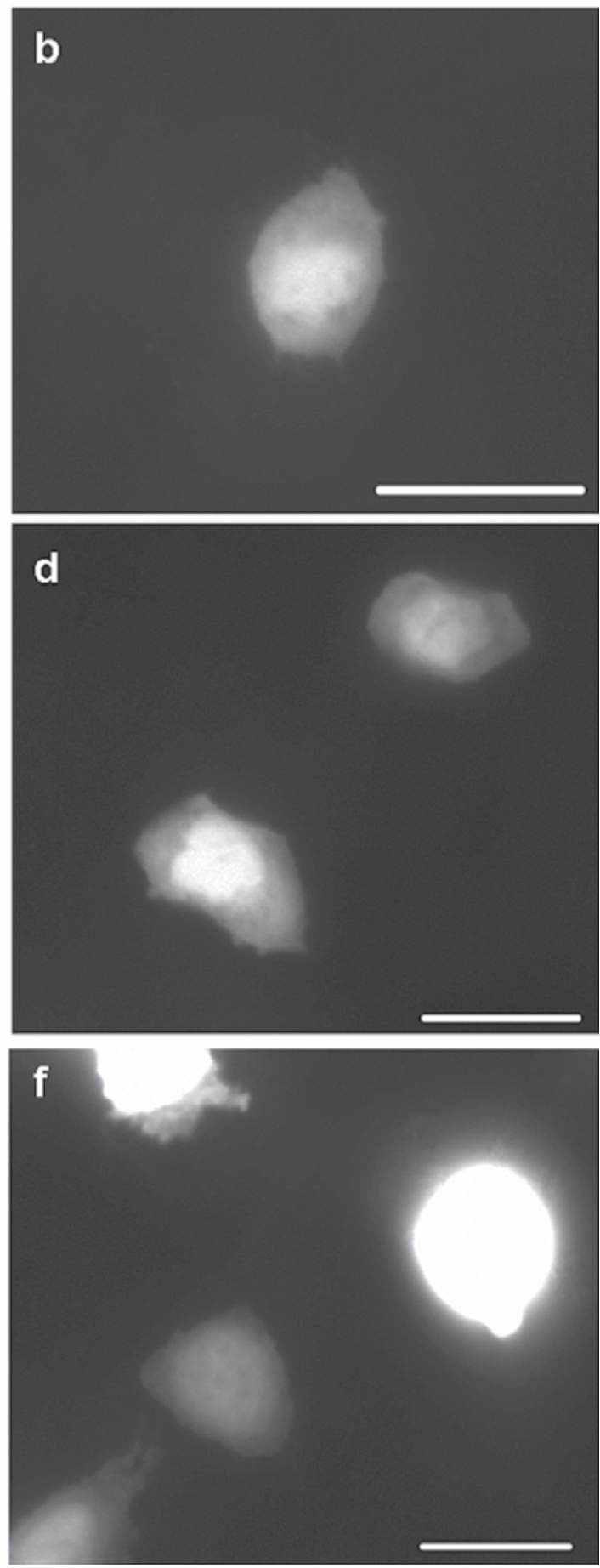

Figure 8: Effect of temperature on the targeting of Pex3p-GFP in wild type CHO cells. Wild type CHO cells were transiently transfected with the GFP (b, d and f) or PEX3-GFP (a, c and e) genes, and subsequently incubated for $14 \mathrm{~h}$ at $10{ }^{\circ} \mathrm{C}$ ( $\mathrm{a}$ and b), $15{ }^{\circ} \mathrm{C}$ (c and d) or $37{ }^{\circ} \mathrm{C}$ (e and f). After this, the cells were fixed and examined using fluorescence microscopy. Bar $=20 \mu \mathrm{m}$. 

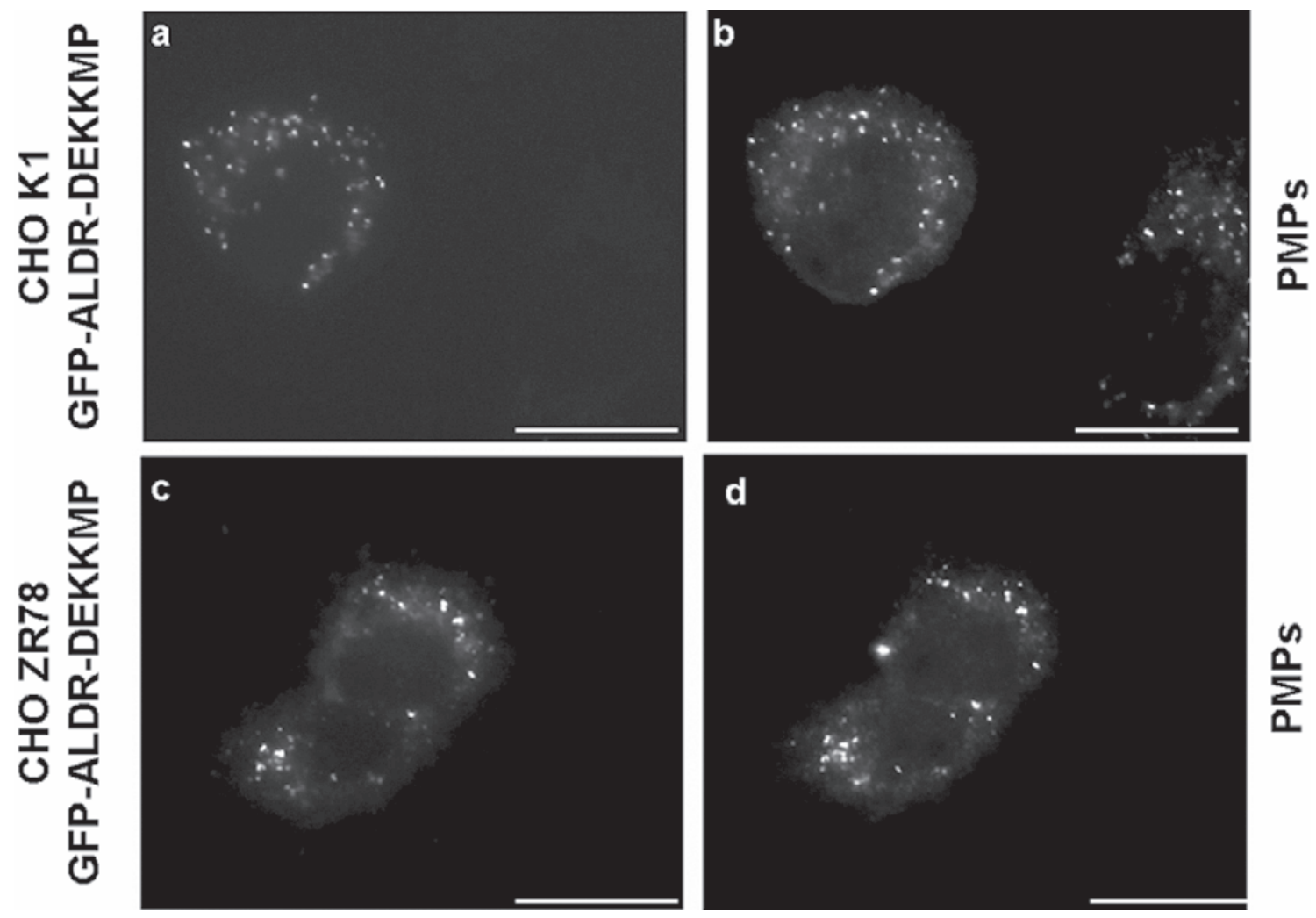

Figure 9: Effect of insertion of an ER retention signal in ALDRP-GFP. Wild type (a and b) and peroxisome biogenesis mutant (ZR 78) CHO cells (c and d) were transiently transfected with the ALDR gene containing an ER retention signal (DEKKMP) fused to GFP. After $18 \mathrm{~h}$, the cells were fixed and treated for immunofluorescence, using antibodies against PMPs (b and d). Bar $=20 \mu \mathrm{m}$.

Under these conditions, the following results support that the classical ER-Golgi transit does not play a major role in biogenesis of resident PMPs. First, targeting of newly synthesized ALDRPGFP, GFP-PMP70 (1-180) or Pex3p-GFP to peroxisomes was not inhibited in the presence of BFA and no accumulation of these proteins in ER-like membranes was observed in the presence of BFA (Figs. 47). Second, the number of peroxisomes was also not affected by the incubation with BFA (Fig. 2), suggesting that vesicle formation from ER in a BFA sensitive manner is not required for the biogenesis of resident PMPs. Recently, South and Gould (1999) showed that BFA also did not block the targeting of Pex16p to peroxisomal membranes in human fibroblasts. Pex16p, which is one of the factors involved in peroxisomal membrane assembly, was targeted to peroxisomes $2 \mathrm{~h}$ after microinjection of the gene into the nucleus of normal human fibroblasts in the presence of BFA. Therefore, ER-Golgi transit seems not to be essential for the biogenesis of peroxisomal resident membrane proteins as well as PMPs involved in peroxisomal membrane assembly in animal cells.

Further, the following evidences support the above conclusion. It is well known that low temperature blocks ER exit of vesicles and retards the vesicle flow to the Golgi apparatus (Mezzacasa and Helenius, 2002). Specifically, the incubation at 10 and $15^{\circ} \mathrm{C}$ can arrests the viral glycoprotein VSVG at ER exit sites and ER-Golgi ts intermediate compartment, respectively (Mezzacasa and Helenius, 2002). Under these conditions, however, the Pex3-GFP protein was imported to peroxisomes (Fig. 8), and no ER-like signal was detected (data not shown). 
To evaluate an eventual transit of PMPs via ER, we also constructed a chimeric gene fusing the ALDRP-GFP and Pex3p with an ER retention sequence signal (DEKKMP), which retains newly synthesized plasma membrane proteins in the ER (Jackson et al., 1990). Specifically, this short sequence when added to the cytoplasmic tail of membrane bound proteins that follow the exocytic pathway, can confer ER residency (Jackson et al., 1990). Our results show that ALDRP and Pex3p, both carrying an ER retention signal on their C-terminus (supposedly oriented to the cytosol), are properly targeted to peroxisomes, in $\mathrm{CHO}$ cells, and do not colocalize with ER (Fig. 10). One possible explanation for these results, is that both chimeric proteins indeed transit via ER, but accumulate in specific regions of ER where the mechanism used for the DEKKMP retention sequence is not active. This specific local accumulation of PMPs in ER membrane, has been shown for yeast (Hoepfner et al., 2005).

We also addressed whether newly synthesized PMPs target to peroxisomal membrane ghosts. Several CHO cells carrying mutations in PEX genes have been isolated and they represent cellular models for PBD (Yanago et al., 2002). The majority of these $\mathrm{CHO}$ mutants, belonging to different complementation groups, show the presence of peroxisomal membrane ghosts, similar to the ones described in Zellweger Syndrome (Santos et al., 1988), the prototype of PBD. These peroxisomal ghosts are the result of defects in the import machinery of peroxisomal matrix proteins. No studies have been previously reported of in vivo targeting of resident PMPs to these peroxisomal ghosts. Our studies clearly showed that ALDRP-GFP, PMP70(1-180) and $P$ ex $3 p$ are correctly targeted to peroxisomal ghosts in $\mathrm{CHO}$ cells mutant in the PEX2 gene (Thieringer and Raetz, 1993) in the presence or absence of BFA (Figs. 5-7). These results suggest that the classical ER-Golgi pathway does not play a major role in the biogenesis of mammalian PMPs and newly synthesized PMPs are preferentially transported to preexisting peroxisomes and peroxisomal membrane ghosts.
Our previous study also supports that the ER-Golgi transit plays no major role in PMPs targeting to peroxisomes. In pulse-chase experiments, newly synthesized PMP70, another ABC protein on peroxisomal membranes, has been shown to be targeted to peroxisomes directly from the cytosol in H4IIE cells, although most proteins, which enter the ER, do so cotranslationally and are never present in the cytosol fraction (Imanaka et al., 1996). It has been also suggested that Pex 19p binds newly synthesized PMPs including PMP70 and ALDP, and facilitates their insertion into peroxisomes (Matsuzono et al., 1999; Sacksteder et al., 2000).

A "de novo" peroxisome biogenesis model has been recently raised as an alternative way to explain several findings that the biogenesis model of growth and division of pre-existing peroxisomes cannot explain. Among these findings, the more relevant is that Zellweger patients lacking normal peroxisomes, peroxisome membrane ghosts or any remnant organelle membrane, restore normal peroxisomes by reintroduction of the wild type PEX gene (South and Gould, 1999). A specific role for the ER has been postulated in the initial steps of peroxisome formation, not only as the source of lipids for peroxisome membranes, but also the site of first appearance of specific PMPs (Kunau, 2005). Moreover Hoepfner et al. (2005) showed in the yeast Saccharomyces cerevisiae that peroxisome generate from the ER, as small vesicles carrying at least two early peroxins, Pex $3 p$ and Pex 19p, budding from specific domains of the ER. Very recently Kim et al. (2006) showed that the early peroxin Pex16p can be targeted to peroxisomes and is cotranslationally inserted into the ER. In addition, this protein can recruit into the ER other PMPs, like PMP34 and Pex3p.

Our experiments cannot rule out the possibilities that peroxisomes form by budding from the ER in a BFA-independent way not inhibited by low temperature. However, we can suggest that the classical ER-Golgi transit is not involved in the transport of several PMPs. In fact, Scheckman has suggested that peroxisomes may be derived from the ER using a new branch of the secretory pathway (Schekman, 2005). 


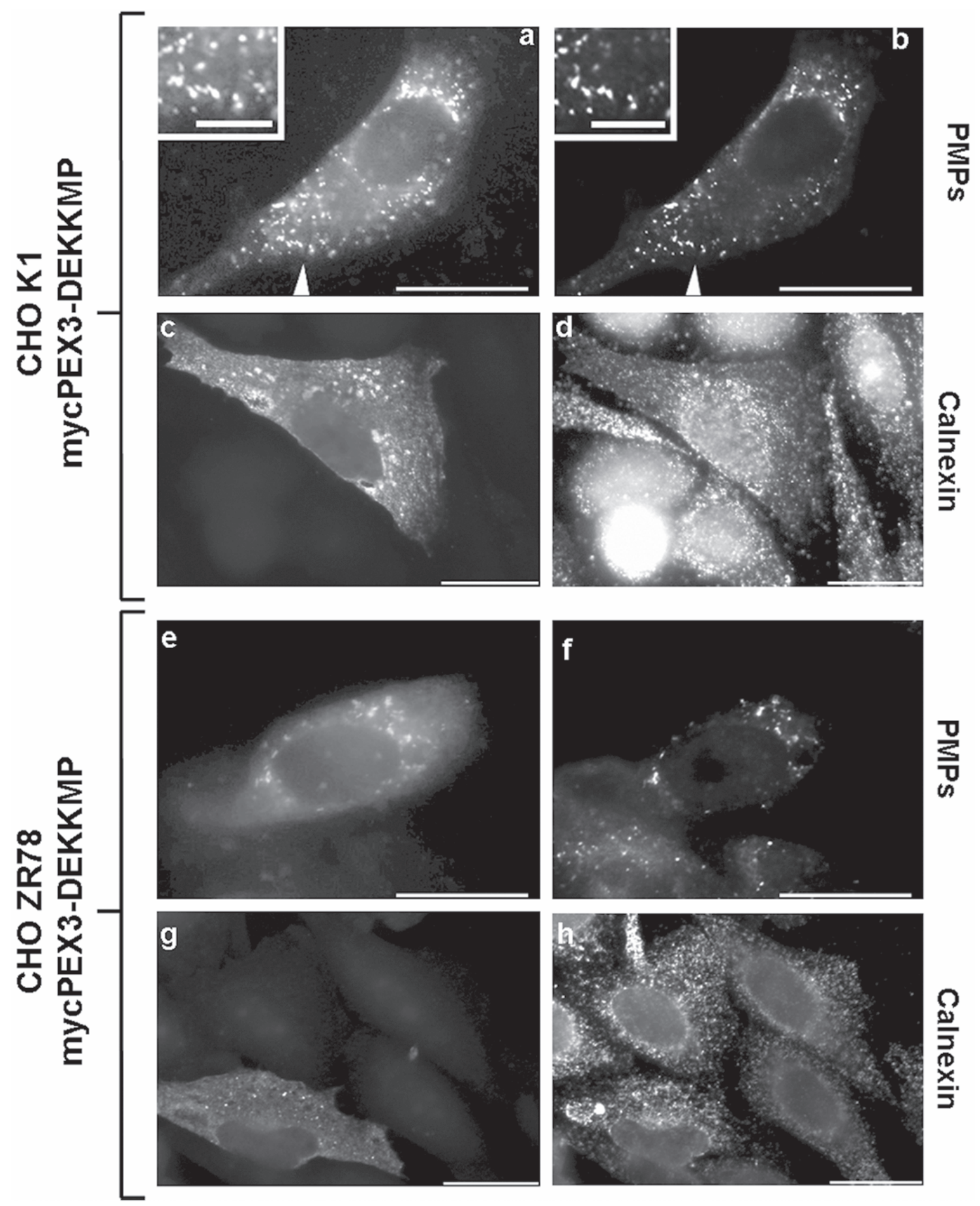

Figure 10: Effect of insertion of an ER retention signal in mycPex3p. Wild type (a-d) and peroxisome biogenesis mutant (ZR 78) $\mathrm{CHO}$ cells (e-h) were transiently transfected with the construct myc-PEX3-DEKKMP. After $18 \mathrm{~h}$, the cells were fixed and treated for double immunofluorescence, using antibodies against PMPs and epitope myc (a-b and e-f), or against calnexin and epitope myc (c-d and g-h). Bar $=20 \mu \mathrm{m}$. Inset bar $=5 \mu \mathrm{m}$. 


\section{ACKNOWLEDGMENTS}

\section{Supported by FONDECYT 1040792 to MJS} and by a Grand-in-Aid for "the Research Committee for Ataxic Diseases" of the Research on Measures for Intractable Diseases from the Ministry of Health, Welfare and Labours, Japan to TI.

\section{REFERENCES}

BIERMANNS M, GARTNER J (2001) Targeting elements in the amino-terminal part direct the human $70-\mathrm{kDa}$ peroxisomal integral membrane protein (PMP70) to peroxisomes. Biochem Biophys Res Commun 285: 649-655

BODNAR AG, RACHUBINSKI RA (1991) Characterization of the integral membrane polypeptides of rat liver peroxisomes isolated from untreated and clofibrate-treated rats. Biochem Cell Biol 69: 499-508

DE DUVE C, BAUDHUIN P (1966) Peroxisomes (microbodies and related particles). Physiol Rev 46: 323-57

DISTEL B, ERDMANN R, GOULD SJ, BLOBEL G, CRANE DI, CREGG JM, DODT G, FUJIKI Y, GOODMAN JM, JUST WW, KIEL JA, KUNAU WH, LAZAROW PB, MANNAERTS GP, MOSER HW, OSUMI T, RACHUBINSKI RA, ROSCHER A, SUBRAMANI S, TABAK HF, TSUKAMOTO T, VALLE D, VAN DER KLEI I, VAN VELDHOVEN PP, VEENHUIS M (1996) A unified nomenclature for peroxisome biogenesis factors. J Cell Biol 135: 1-3

FUJIWARA T, ODA K, YOKOTA S, TAKATSUKI A, IKEHARA Y (1988) Brefeldin A causes disassembly of the Golgi complex and accumulation of secretory proteins in the endoplasmic reticulum. J Biol Chem 263: $18545-52$

GOULD SJ, VALLE D (2000) Peroxisome biogenesis disorders Genetics and cell biology. Trends Genet 16: 340-345

HEILAND I, ERDMANN R (2005) Biogenesis of peroxisomes. Topogenesis of the peroxisomal membrane and matrix proteins. FEBS J 272: 2362-2372

HELMS JB, ROTHMAN JE (1992) Inhibition by brefeldin A of a Golgi membrane enzyme that catalyses exchange of guanine nucleotide bound to ARF. Nature 360: $352-354$

HOEPFNER D, SCHILDKNEGT D, BRAAKMAN I, PHILIPPSEN P, TABAK HF (2005) Contribution of the endoplasmic reticulum to peroxisome formation. Cell 122: 85-95

HOLZINGER A, KAMMERER S, BERGER J, ROSCHER AA (1997) cDNA cloning and mRNA expression of the human adrenoleukodystrophy related protein (ALDRP), a peroxisomal $\mathrm{ABC}$ transporter. Biochem Biophys Res Commun 239: 261-264

HOLZINGER A, MAYERHOFER P, BERGER J, LICHTNER P, KAMMERER S, ROSCHER AA (1999) Full length cDNA cloning, promoter sequence, and genomic organization of the human adrenoleukodystrophy related (ALDR) gene functionally redundant to the gene responsible for Xlinked adrenoleukodystrophy. Biochem Biophys Res Commun 258: 436-442

IMANAKA T, SHIINA Y, TAKANO T, HASHIMOTO T,
OSUMI T (1996) Insertion of the 70-kDa peroxisomal membrane protein into peroxisomal membranes in vivo and in vitro. J Biol Chem 271: 3706-3713

IMANAKA T, AIHARA K, TAKANO T, YAMASHITA A, SATO R, SUZUKI Y, YOKOTA S, OSUMI T (1999) Characterization of the $70-\mathrm{kDa}$ peroxisomal membrane protein, an ATP binding cassette transporter. J Biol Chem 274: 11968-11976

JACKSON MR, NILSSON T, PETERSON PA (1990) Identification of a consensus motif for retention of transmembrane proteins in the endoplasmic reticulum. EMBO J 9: 3153-3162

KAMMERER S, HOLZINGER A, WELSCH U, ROSCHER AA (1998) Cloning and characterization of the gene encoding the human peroxisomal assembly protein Pex3p. FEBS Lett 429: 53-60

KASHIWAYAMA Y, ASAHINA $\mathrm{K}$, SHIBATA $\mathrm{H}$, MORITA M, MUNTAU AC, ROSCHER AA, WANDERS RJA, SHIMOZAWA N, SAKAGUCHI M, KATO H, IMANAKA T (2005) Role of Pex19p in the targeting of PMP70 to peroxisome. Biochem Biophys Acta 1746: 116-128

KIM PK, MULLEN RT, SCHUMANN U, LIPPINCOTTSCHWARTZ J (2006) The origin and maintenance of mammalian peroxisomes involves a de novo PEX16dependent pathway from the ER. J Cell Biol 173: 521-32

KUNAU W, ERDMANN R (1998) Peroxisome biogenesis: back to the endoplasmic reticulum? Curr Biol 8: R299302

KUNAU W (2005) Peroxisome biogenesis: end of the debate. Curr Biol 15(18): R774-776

LAZAROW PB, FUJIKI Y (1985) Biogenesis of peroxisomes. Ann Rev Cell Biol 1: 489-530

LIPPINCOTT-SCHWARTZ J, YUAN LC, BONIFACINO JS, KLAUSNER RD (1889) Rapid redistribution of Golgi proteins into the ER in cells treated with brefeldin A: evidence for membrane cycling from Golgi to ER. Cell 56: 801-13

MATSUZONO Y, KINOSHITA N, TAMURA T, SHIMOZAWA N, HAMASHAKI M, GHAEDI K, WANDERS RJK, SUZUKI Y, KONDO K, FUJIKI Y (1999) Human PEX19: cDNA cloning by functiona complementation, mutation analysia in a patient with Zellweger syndorome and potential role in peroxisomal membrane assembly. Proc Natl Acad Sci USA 96: 2116-2121

MEZZACASA A, HELENIUS A (2002) The transitional ER defines a boundary for quality wild type in the secretion of tsO45 VSV glycoprotein. Traffic 3: 3833-3849

OGLESBEE D (2005) An overview of peroxisomal biogenesis disorders. Mol Genet Metab 84: 299-301

SACKSTEDER KA, JONES JM, SOUTH ST, LI X, GOULD SJ (2000) PEX19 binds multiple peroxisomal membrane proteins, is predominantly cytosolic, and is required for peroxisomal membrane synthesis. J Cell Biol 148: 931-44

SALOMONS FA, VAN DER KLEI IJ, KRAM AM, HARDER W, VEENHUIS M (1997) Brefeldin A interferes with peroxisomal protein sorting in the yeast Hansenula polymorpha. FEBS Lett 411: 133-139

SANTOS MJ, IMANAKA T, SHIO H, SMALL GM, LAZAROW PB (1988) Peroxisomal membrane ghosts in Zellweger Syndrome-Aberrant organelle assembly. Science 239: 1536-1538

SCHEKMAN R (2005) Peroxisomes: another branch of the secretory pathway? Cell 122: 1-7

SOUKUPOVA M, SPRENGER C, GORGAS K, KUNAU WH, DODT G (1999) Identification and characterization of the human peroxin PEX3. Eur $\mathrm{J}$ Cell Biol 78: 357-74 
SOUTH ST, GOULD SJ (1999) Peroxisome synthesis in the absence of preexisting peroxisomes. J Cell Biol 144: $255-266$

SOUTH S, SACKSTEDER KA, LI X, LIU Y, GOULD SJ (2000) Inhibitors of COPI and COPII do not block PEX-3-mediated peroxisome synthesis. J Cell Biol 149: $1345-1359$

THIERINGER R, RAETZ CR (1993) Peroxisome-deficient Chinese hamster ovary cells with point mutations in peroxisome assembly factor-1. J Biol Chem 268: 12631-12636

TITORENKO VI, RACHUBINSKI RA (1998a) The endoplasmic reticulum plays an essential role in peroxisome biogenesis. Trends Biochem Sci 23: 231233

TITORENKO VI, RACHUBINSKI RA (1998b) Mutants of the yeast Yarrowia lipolytica defective in protein exit from the endoplasmic reticulum are also defective in peroxisome biogenesis. Mol Cell Biol 18: 2789-803

TITORENKO VI, RACHUBINSKI RA (2001) Dynamics of peroxisome assembly and function. Trends Cell Biol 11: $22-29$

VAN DEN BOSCH H, SCHUTGENS RBH, WANDERS RJA, TAGER JM (1992) Biochemistry of peroxisomes. Annu Rev Biochem 61: 157-197

VOORN-BROUWER T, KRAGT A, TABAK HF, DISTEL B (2001) Peroxisomal membrane proteins are properly targeted to peroxisomes in the absence of COPI- and COPII-mediated vesicular transport. J Cell Sci $114(\mathrm{Pt}$ 11): $2199-204$
WANDERS RJ (2004) Metabolic and molecular basis of peroxisomal disorders: a review. Am J Med Genet 126: 355-375

WEI H, KEMP S, MCGUINNESS M C, MOSER A B, SMITH K D (2000) Pharmacological induction of peroxisomes in peroxisome biogenesis disorders. Ann Neurol 47: 286-296

WIELAND F, HARTER C (1999) Mechanisms of vesicle formation: insights from the COP system. Curr Opin Cell Biol 11: 440-6

YAMASAKI M, HASHIGUCHI N, FUJIWARA C, IMANAKA T, TSUKAMOTO T, OSUMI T (1999) Formation of peroxisomes from peroxisomal ghosts in a peroxisome-deficient mammalian cell mutant upon complementation by protein microinjection. J Biol Chem 274: 35293-6

YANAGO E, HIROMASA T, MATSUMURA T, KINOSHITA N, FUJIKI Y (2002) Isolation of Chinese hamster ovary cell pex mutants. Biochem Biophys Res Commun 293: 225-230

ZHAO L, HELMS JB, BRUGGER B, HARTER C, MARTOGLIO B, GRAF R, BRUNNER J, WIELAND FT (1997) Direct and GTP-dependent interaction of ADP ribosylation factor 1 with coatomer subunit beta. Proc Natl Acad Sci U S A 94: 4418-23

ZOELLER RA, ALLEN LA, SANTOS MJ, LAZAROW PB, HASHIMOTO T, TARTAKOFF AM, RAETZ CRH (1989) Chinese Hamster Ovary (CHO) mutants defective in peroxisome biogenesis: comparison to Zellweger Syndrome. J Biol Chem 264: 21872-21878. 
